\title{
Modern Paradigms in Education under Social and Cultural Challenges
}

\author{
Maksim Kochetkov \\ Institute of Continuous Education of Siberian Federal University \\ Krasnoyarsk Institute of Economics - branch of Saint-Petersburg University of Management and Economics \\ Krasnoyarsk, Russia \\ E-mail: m-kochetkov@yandex.ru
}

\begin{abstract}
This paper will study the social and cultural changes in the society which could demand the adequate transformations of the higher school. There are justified main characteristics of the spiritual and creative paradigm suggested for all the levels of education. By doing so, there are proven statements of the creative and innovative paradigm for higher school which is oriented to integration with the production activity, social projects in the society, and the development of great number of cultural activities.
\end{abstract}

Keywords-creative and innovative paradigm in education; spiritual and creative paradigm; competence approach; higher school; cultural activities

\section{INTRODUCTION}

The modern society is characterized by the increasing rate of the social and cultural changes to which the system of education has to react that could result in the changing of the development strategy. It is logical to analyze the paradigm tendency as the means to define the relevant methodology for the development of education in the context of the most significant social and cultural transformations. N.N. Yaroshenko is right to state, while studying the pedagogy paradigms, that "with the changing of the social and cultural situation in the country the standards of the scientific explanation of the pedagogical knowledge, the perception of reality in science, the styles of thinking which are formed in the context of culture change too" $[21,6]$. We should stress that according to the statement by N.G. Agapova "there is absent the only 'right' paradigm of education - the simultaneous existence of several paradigms is the characteristic feature of education today; within one paradigm there could exist (co-exist) and develop different modes of education; there could be integration and synthesis of different modes and paradigms in the frame of the single educational space" [1, 312]. Taking into account the things mentioned above, the detection and, if necessary, the justification of the educational paradigm which are the most adequate ones to the modern social and cultural challenges of today is of methodological significance for the development of the education system and higher education in particular.

\section{THE COMPETENCE APPROACH - ADVANTAGES AND DISADVANTAGES}

In the theory of the Russian pedagogy beginning from the 1990s the observation is made that the tendency to justify the great number of different education paradigms including the past, present, and the future (the forthcoming education paradigms) $[1 ; 9 ; 12 ; 14]$; the paradigm approach in education is considered to be the urgent topic to discuss [9; $12 ; 14]$. The fact mentioned is the evidence that the social and cultural environment, beginning from the 1990s, has varied much and its interpretation was different in the pedagogical society. The 15 th-year reformation of the higher school under the Bologna process and the competence approach implementation led to the greater importance of this approach for the new paradigm of education. We should agree that the competence approach deserves more attention at least due to its definite practical implementation.

However, it is the efficiency of its practical implementation which is doubted by some scientists. Thus, A.S. Pobotova states the absence of strong arguments due to observing the professional career of the graduates (not undergraduates) to prove its expediency — in the numerous dissertations and monographs there were mentioned mostly undergraduates, but not the experienced specialists [16, 48]. A.L. Andreev has even more categorical opinions: "the implementation of the competence approach as the new paradigm didn't lead to ever significant improvement of the graduates' competences but, on the contrary, it showed the decrease in the level of competences" [2,32]. A.M. Novikov, the academician of the Academy of Sciences of Russia, stresses: "Competences, actually, are the synonyms of skills. ...In the Russian pedagogy and psychology very long ago there was done the theory of skills formation. What is more, beginning from the E. A. Mileryan's works (70-s of the XX century) skills were defined not as technology signs but as complicated structural formations including emotional, intellectual, strong-willed, and features of personality providing the accomplishment of the goals done under changing conditions" [13, 74].

In the middle of the last century (and even in earlier periods) there also existed the idea of the close connection of teaching and practical training in the teaching society as well 
as necessity of practical tasks solution and the understanding that one should be able to do rather than to know how to do. We could not say that the situation has changed much for the better in this respect in the system of higher education, on the contrary, it is worse (especially in the field of sciences education). Maybe, this is the reason of the competences level decrease mentioned by Professor A.L. Andreev. But when speaking about the formation of competences, suggesting new education technologies, scientists never mention the fact that in most cases they deal with semiprofessional activities, as A.S. Robotova said.

Some differences between competences and skills, as A.M. Novikov says, do exist: competences in the works of the contemporary scientists differ from skills in motifs. The academician comments: "If we include motifs in competences (and with the competence approach they are to be included into curriculum) then the motifs will be the part of the content of education! This would mean that the motifs of undergraduates and later the motifs of graduates must be similar that could be regarded as the violation of personal freedom! ... The fact that the motifs for the Americans (and the Europeans) are included into the competences is not an accidental one. It reflects dangerous tendencies in the development of the Western civilization..." [13, 64]. Actually, the strictly structured formation of the similar motifs couldn't be regarded as the personality-orientated tendency which has been mentioned in the world scientific papers dedicated to the problems of education recently.

The warnings by A.M. Novikov, the academician of the Academy of Sciences of Russia, had not been heard - today the motifs included into to the competences are in the education standards and curriculum. Professor A.L. Andreev writes to comment on the situation: "Mixture of knowledge with personal characteristics and the level of socialization, and professional skills with values is typical both for the competence approach and for the regulatory papers, for example, for the Federal state education standards which makes the set of aims in education extremely indistinct and even chaotic" [2, 33]. It could be partially explained by the fact that for the students there is great difference between statements "I can do and want to do", "I want to do but I can't do", "I can do but I don't want to do" and "I can't do and I don't want to do" because the ability to do something and the motivation to do something are formed in different ways and by different teachers [2, 33]. Besides, the formation of motivation has the marked physiological base, it depends on the variety of factors beyond the education space.

The scientist gives a few more arguments to show inconsistency of the competence approach as the education paradigm. Thus, A.L. Andreev points out that the notion of "competence" could not be used for all mental and subjectmatter abilities realized in human activity: "How, for example, could one characterize the level of creative imaging or the talent of an artist with the help of this notion? " [2,32].

A lot of questions could be raised by the fact that "in spite of the initial thoughts of the theory, men of the competency, approach the notion "competence" as the wide notion is not so easy to turn into the operational notion. This means that unlike the classic triad set of "knowledgeabilities-skills", the level of competences formed is very difficult, if ever possible, to control in many cases" [2,35]. As the result, "all the tests defined as assessment tools beginning from the Federal State Examination Set of Tests and to the tests to assess the knowledge of the undergraduates is just the tool to check knowledge only" [2, 35].

\section{ANTHROPOCENTRIC CHARACTERISTIC OF FORTHCOMING EDUCATION PARADIGM}

We should not continue the permanent discussion $[2 ; 3 ; 6$ : $10 ; 16 ; 18]$ concerning the advantages and disadvantages of the competence paradigm. With no application to deep justification we try to give our own perception of the forthcoming education paradigm whish should stem from the current education paradigm both in justifying itself in its aims and achievements and in not justifying hopes to open the possibilities to accomplish the tasks taking into account social and cultural peculiarities in the development of the society and education in particular.

Innovation character of human activity is the sign of the time - the era of the postindustrial society. The conception of the postindustrial society was done by D. Bell in 1973 and it included such ideas of the postindustrial community as creation of service economy, dominance of the layer of scientific workers, wide spread of "intellectual" equipment, and the prevailing role of the theoretical knowledge as the source of innovation [4]. After 40 years we could mention also such signs as the increase of frustrating factors to humanity, stresses and depressions which take the first place among the disorders in Russia and which could become the main reason of mass disability in this country [5]. This is why the adequate reaction of the social institutes to the postindustrial changes in the society is the tendency towards the anthropocentricity of innovations and this principle should be considered to be the main criteria in the efficiency of the changes in the society in the postindustrial epoch. Innovations as they are should not be considered as the main objective.

Pedagogical support of human activity, namely, the creation of conditions for development and the selfdevelopment of individuals both in creative productivity and in socio-psychological readiness to live under a fastchanging society is one of the evident trends to reduce sociopsychological frustrations and the precondition in anthropocentricity of innovative changes. That is why the most urgent trends in pedagogical support are connected with the teaching of creativity, psychologically comfortable involvement in the innovative environment as well as with new additional means of professional activity (new communication means, Internet and etc.).

\section{CREATIVE INNOVATIVE EdUCATION PARADIGM IN HIGHER EDUCATION}

We could name more urgent pedagogical factors to improve higher education mostly due to greater usage of the 
principle of anthropocentricity of innovations. However, at present the possibilities of their effective practical realization, in our opinion, are closely connected with the judgment of the new education paradigm, the creative innovative one, the complete set of principles and conceptual regulations which define the perspective strategy of higher education development.

The notion of innovation in the works of scientists, as a rule, imply constructability of innovations for a man. No doubt that any theory of man of innovatics would deny the statement done by a famous poet of Russia Andrew Voznesenskiy: "Any progress is reactive if a man is hurt".

However, contradictions, socio-frustrating influence of different factors are the moving power of human development. Constructability or destructiveness of innovations, their reaction character or positive influence on a man couldn't be defined in a concrete way anytime. This is, as a rule, a complicated issue which is accompanied by "conflict constructions of solved contradiction" while considering it [23], the whole spectrum of the universal structure, the man's place in nature and in society, the place of the definite community in the system of federal, national, religious, and other field in cultures and communities with their peculiarities and aspirations.

The principle of anthropocentricity of innovations needs special comments from the point of moral expediency of innovations. On one hand, innovative activity should be anthropocentric in the sense which is in the sited sentence by Andrew Voznesenskiy. On the other hand, a man is a part of nature, his understanding of himself and the world around is the unity of the individual and in general, anthropocentricity is not good in this situation and it could harm the man. By measuring his wishes, needs, satisfied with innovations, only with his "essence" he could harm another Man or harm the environment that generated him and the part of which he still is.

Consideration of innovative processes in education simplifies to some extent the task to define the constructability of innovations because the management of innovative activity in higher school is not directly connected with natural environment (if we don't consider the level of definite innovative projects). That is why the suggested principle of anthropocentricity of innovative changes as the main criteria to reform higher education implies, first of all, minimization of socio-psychological frustrating factors which could accompany innovations. The measures to compensate destructive influence of the changes in the institutional forms of educational space on the participants of educational activity.

For the system of education and the Russian society on the whole there is the task of advanced innovative development of economy with social stability which implies the balanced subject-disorientated tendency of man's potential and his creativity.

Philosophical conceptions of creativity see the novelty as the criteria characteristic of creative work not only in the result of activity but in the process itself which could be described with the help of such notions as longevity, intersubjectivity, polyphony, interparadigm process, etc. Besides, in non-classic tradition the creative process and its results are added with anthropological and social aspects [17].

Creative and innovative activities coincide in essence. They are initially synonymous. Gradually the notion "innovation" was used together with innovations realized in this or that field of human activity. By "innovation" one meant the complicated process of development managed by a man that is used by society and its institutions directly aiming at progress and positive result in this or that sphere of life $[19,35]$. By doing so, in classical variant the changes stem from the field of fundamental knowledge, then they continue in the scientific and technical spheres and finish in the consumer environment with socially effective results. By "innovative development" one implies "gradual and expedient forward movement, achievement of new social quality on the base of innovations in different fields of community life" $[19,36]$, in education as well (in educational environment, in educational space).

The notion "creative work" doesn't exclude its usage for complicated processes of interconnected and purposed initiated changes.

Some authors use "creative work" and "innovation" only in positive meaning implying the socially significant results are achieved. But this is not correct. Thus, criminal activity could also be characterized by creative solutions. "Bicycle invention" is either not for the present progress of society, however, such creative work is sometimes very important in the teaching process, being the factor to cause the appearance of such innovations which have never been known for mankind ever since.

Thus, creative work is a much more general notion; this category is better foe methodology level of investigation of humanity problems in social and cultural educational environment than the category "innovation". What is more, under the conditions of modern socio-cultural challenges of the time (both in Russia and elsewhere in the world) it is the formation of spiritual and creative potentials of personality [7] but not only the creative individual can be of greater urgency which would be mentioned further.

The phrase "creative and innovative" is caused by understanding that the innovative educational environment of higher school is the environment oriented to the integration of productive activity and the solution of practical problems. In this sense the creative and innovative environment of higher school could be opened for undergraduates in all its planes closer to the senior courses.

The institutional forms of educational space which are adequate to modern innovative demands for higher education are the management and organization of the teaching and vocational processes, methodology, and research activity in higher school based on the creative and innovative paradigm; it is the factor which would give a teacher the possibility to choose forms and techniques of teaching, methodological work, scientific activity, and professional self-development. Let's name the mentioned forms as creative and innovative 
ones. The adequate positive experience exits: some universities in the country literally open their doors for innovative business, enterprising initiatives, cooperation with research institutes and workshops. They could be named "enterprising universities" [8] and the corresponding institutional forms as "cluster models" [20].

If in the educational environment of higher school there is actively used cluster institutional formats, this environment will then be characterized with "associative principle of cooperative activity rather than corporative principle which dominates in universities today. In an association, horizontal ties play an important part, but in a corporation vertical ones are important. The dominance of vertical ties leads first to weakening of horizontal ties of departments and then to the situation when the real cooperation is liquidated. In universities of today even the leading departments don't know and don't want to know what their collaborators deal with" [22, 208].

Changing of the present situation at the institutional level is connected with overcoming the principle of individual management of creative workshops, with developing cooperation among several workshops (personal academies, creative and innovative clusters, workshops), centers of mutual usage of research and production equipment, and intellectual data bases [22, 208].

The main problem is that the positive experience in realization of cluster models, being the result of titanic efforts of better representatives from the teaching circles, is restricted to qualitative development, the appearance of system effects from innovative initiatives - because there is preserved conservatism in methodology of education system. The logics of the competence-oriented contend of education in spite of paradigm reorientation from the level of knowledge to the level of skills to perform activity, team work, etc., causes to regulate educational process, which is cluster and an open one. The institutional forms in higher education could neglect the effect from creative and innovative institutional forms. The latest speech by President V.V. Putin where there was mentioned the creation of international university of corresponding countries on the base of distant learning for millions of people wishing to become students (!) sounds disturbing.

\section{SPIRITUAL AND CREATIVE EdUCATIONAL PARADIGM}

Distant learning is becoming an integral part of modern educational technologies. The new type of an e-University which unites different educational establishments and teaching staff on the base of general standards, agreements and technologies where e-learning is realized has become the reality. The module-type system of education in the context of the competence approach and module-rated assessment of education quality typical for the western countries is rather favorable for the distant learning development. Therefore, starting from the year 2003 there has been realized the strategy named eBologna (electronic Bologna). Its task is implementation of electronic and blended education, such as virtual mobility, which would favor combined competences, and flexibility in long-life education.
However, the main task of today and for the future is a reasonable balance between classroom teaching and the teaching done in the electronic environment. The criteria of the mentioned balance are indefinite because they are directly connected with interpersonal aspects of the human cognitive activity, and in socio-cultural context - the axiological sphere of man and society, which are difficult to attach to definite technologies (distant technologies are among them). In the decree by the President "Ratification of regulatory rules in the Federal cultural politics" there is stressed the specific role in the formation of the system of the Russian orthodox values. By the Constitution of Russian Federation none of ideologies can be considered to be as obligatory one and that is why ideological functions in the Russian society are performed by mental peculiarities of the peoples of Russia which had been brought up in the cultural and historical development. These values were defined at the XVIII World Russian People Congress and later they were developed in the speech by Patriarch Cyrill in Duma on the 22 of January 2015. They are belief, great power statehood, justice, respect of rights and freedoms of man, his dignity, "the society of solidarity" where different ethnic, cultural, social, vocational, religious, and age-grouped communities cooperate with each other to achieve the good for everybody.

In the system of education the mentioned values should be developed due to the cultural practices based on humanitarian education, mostly on the base of universities and the art academies, and other humanitarian educational institutions. By the cultural practices, one means, the human activity characterized by project-aimed cultural constituent. Implementation of cultural (socio-cultural) practices into education implies a decrease of narrow subject-matter restrictions in the formation of cultural experience, simultaneous application of different fields of culture, and development of common cultural abilities. Creative and innovative paradigm of higher education would lead to the widest integration of cultural practices with social projects under way as well as initiation of different innovative projects for cultural practices development aimed at all layers of population and the youth the first group of emphasis.

On the whole, the active part of the education system must be aimed at the axiology results. Here the greatest potential is hidden in the interaction of subjects of educational process. Spiritually oriented cooperative (cocreative) teaching is phenomenon caused, mostly, by personal influence, the influence of the deepest sides of the nature of man, which are obscure, even in "face-to-face" communication and which are determined by potential hidden abilities of an individual. Everything that is connected with spiritual and cultural development is closer to the up-bringing process rather than to teaching process, closer to arts than to technology, to the spiritual, and "live" personal influence than to distant Internet0communication. It is in the atmosphere of the multiplane existence environment created by a student and a teacher which escaped from assessment but not its virtual-digital similarity there is hidden the secret of the efficiency in spiritual and cultural development of subject of educational process, the formation 
of his personal creative constituent. To prove it let us remind the names of V.I. Vernadskiy, A.F. Iyoffe, P.L. Kapitsa, S.P. Korolyov, I.V. Kurchatov, L.S. Landau, A.G. Rubenshtein. The representatives of these scientific schools stated that the creative atmosphere itself caused by personal mutual influences promoted their creative inspirations.

In this context, we cite the words by A.L. Andreev to show the urgency of education paradigm changing: "Russian theory men of the competence approach don't take into account the fact that not everything we know and can do (or we must know and be able to do) could be expressed explicitly and given to students in the way available to check and assess with the help of qualimetric scales. The implicit, "personal" knowledge (M. Polany) which an individual forms himself mostly on the base of his practical experience in vocational activity and social contacts is very often the most valuable part of his intellectual baggage" [2, 34]. Some parts of knowledge and competence can be transformed only in the form of personal knowledge [15, 83].

The last statement, in our opinion, is the right one in regarding to upbringing tasks in their separate form from the teaching tasks form: the possibilities of distant moral upbringing are even more restricted than the possibilities of distant learning. The cultural and historical traditions, the spiritual achievements of the people tested by a long history, are to fulfill the regulatory function of the morale in the Russian community. Love to Fatherland, perceive of morale norms included in the best cultural peculiarities of the country and the region - it is the result of the influence, first of all, the very much respected people, rituals, traditions, regulations of the definite educational institution. We should stress that the morale is an important innovational source of the postindustrial society, the condition of positive changes, possibility to realize national projects, innovative programs in the development of regions, and lastly the branches and this country on the whole.

To train specialists who would be able to develop the society in innovative ways it is not proper to use the typical for distant learning testing system, the formal problems, the Internet communication, the efficiency of which decreases with the increase of students. Creative process is not compatible with the great amount of routine work for a teacher and with the solving of typical problems; such education technologies standardize thinking, hinder the development of creative multidiscipline consciousness, the spiritual and creative features, and to say nothing about the skills of personal communication and work in creative groups.

The conclusion done can be considered as the statement which characterizes both creative and innovative paradigm of higher education and spiritual and creative education paradigm which, in our opinion, is urgent for all stages of education that will be discussed further.

Creative and innovative education paradigm promotes the counteraction with many negative trends in education [11]. The additional arguments will be generalized in the context of methodology advantages of the suggested paradigm in comparison with the competence approach (paradigm). Firstly, they are the advantages connected with the category of creative work, namely, with its relevance to the investigation of general personal characteristics which is especially important to consider spirituality, the development of culture and its creature; secondly, the implicit practicallyoriented aim promotes innovative activity in accordance with urgent socio-economic tasks of society development judging from the logics of development of the sciences that base innovations; thirdly, regarding the motivation sphere the development of creative and innovative environment has the purpose to form the creative constituent of a personality that, to some extent, keeps the connection with the competence approach in the motivation sphere. The mentioned connection could enlarge more if in the motivation aspect one would give the main part to the competence approach provided the longed support of the vocational activity of undergraduates and graduates.

The suggested methodology advantages and peculiarities of the creative and innovative education paradigm could be projected in the secondary school as well. In this case there are implied, first of all, pedagogy innovations giving unique educational environment patterns. This way was done successfully by the Russian high schools in the 1990s. However, it made a turn to the direction of standard assessment tools, restricted education standards, typical technologies of education and upbringing, the Federal was very convenient for service men far from education Final Examination system and multilevel reporting activity which itself. However, it would be better to suggest spiritual and creative paradigm for the whole system of education and give the term "creative and innovative" to higher school not to confuse the ideas hidden behind the term "innovation" (pedagogical innovations in high school and practicallyoriented innovations in higher school). The stress on the innovative aspect of the education environment developed in higher school due to connection between the stages of education defines the corresponding set of goals both for high school stage and for primary school stage (realization of socio-economic innovations in Russia which go ahead of its time and formation of creative and innovative potential of a man).

\section{THE MAIN RESUlTS OF THE STUDY}

Thus, orienting to socio-cultural challenges of time we actualized spiritual and creative development of the subjects in teaching process and concerning higher school creative and innovative as well. These were the main defined peculiarities of these educational paradigms. The creative and innovative paradigm oriented to higher school implies, first of all, practically-oriented innovations including both industrial and social projects and cultural practices for wide layers of population. The urgency of anthropocentricity of innovative changes has been proven. The principle of the same name as the criteria of efficiency in innovations in society and in education, as one of the main principles of creative and innovative education paradigm, has been justified. Special attention has been paid to the succession of creative and innovative paradigm and the competence education paradigm. 
Creative and innovative education paradigm of higher school with its principles and conceptual statements promotes the management and organization of the teaching and upbringing processes, methodological and scientific work in higher school which defines the prior forms and directions of the teaching and upbringing, methodological and scientific work, and lastly professional self-development: training and self-training to creative work, modern possibilities of creative education activity, orientation to the cluster models of socio-cultural education environment as the result of project-aimed cooperation with industrial structures, centers of implementation of socio-cultural programs, non-educational research centers, groups to mutual usage of research and industrial equipment, intellectual data bases and bases of innovation ideas, university departments, creative workshops, organizations of socio-cultural profile, and balanced usage of distant learning possibilities among others.

\section{REFERENCES}

[1] Agapova N.G. Paradigm orientations and the models of modern education (system analysis in the context of culture philosophy): monograph. - Ryazan, 2008. - 364 p.

[2] Andreev A.L. The perspectives of education: competences, intellectual environments, transdiscipline character // Higher education in Russia. - № 3. - 2014. - P.30-41

[3] Babintsev B.P. Bureaucratization of regional higher educational establishment // Higher education in Russia. - 2014. - № 2. - P. 3037.

[4] Bel D. Forthcoming postindustrial society. Experience of social forecasting. - M., 1999. $-956 \mathrm{p}$.

[5] Dmitrieva T.B. Psychological health and national security challenges of the 21century // Ecology of psychological health interaction of education, science and practice in modern psychiatry: papers of the All-Russian scientific conference. - Archangelsk, 2008.

[6] Zeer Ae. F., Pavlova Ae. Ae., Syimanyuk E.E. Modernization of professional training: competence approach: Teaching aid book. - M., 2005. - P.11-113

[7] Ignatova V.V. Pedagogical factors of spiritual and creative development of personality in the process of socialization and the conditions of realization: Doctorate dissertation of pedagogical sciences. - Krasnoyarsk, 2000.

[8] Klark B.P. Establishment of business universities: organizational directions of transformation. - M., 2011.

[9] Korshunova N. L. Does pedagogics need new paradigm? // Pedagogics. - 2002. - № 7. - P. 19-26.

[10] Kochetkov M. V. Innovations and pseudoinnovations in higher school // Higher education in Russia. - 2014. - № 3. - P.41-47.

[11] Kochetkov M.V. Creative postindustries in formation of university clusters of new type 9in the context of professional and creative development of a teacher in socio-cultural education environment): monograph. - Krasnoyarsk, 2015.

[12] Kraevskiy V.V. Parade of paradigms (epilogue to the article by N.L. Korshunova) // Pedagogics. - 2006. - № 8. - P. 20-24.

[13] Novikov A.M. The bases of pedagogics. - M., 2010.

[14] Osmolovskaya I. M. About paradigms in pedagogics // Innovations in education. - 2007. - № 2. - P. 20-29.

[15] Polany M. Personal knowledge. - M., 1985.

[16] Robotova A.S. Ambiguous processes in pedagogics of higher school // Higher education in Russia. - 2014. - № 3. - P. 47-54.

[17] Tomuk O.N. The Understanding of Creativity and its Criterions in Classical and Non-classical Philosophy // Journal of Siberian Federal
University. "Humanities". - 2014. - № 7. - Volume 7. - P. 1128 1136.

[18] Tchagapsoev Ch. G. Regional higher educational establishment is not involved in the development strategy of education in the country // Higher education in Russia. - 2014. - № 2. - P. 38-42.

[19] Usmanov B. F. Social innovatics: teaching aid book. - M.: Socium, 2009.

[20] Uryev V.M., Chvanova M.S., Peredkov V.M. University as a center of innovative and educational cluster // Vestnik of Tambov University "Humanities". - Tambov, 2007. - № 5.

[21] Yaroshenko N.N. Pedagogical paradigms of socio-cultural activity theory: Doctorate dissertation of pedagogical sciences. - M., 2000.

[22] Yachin S.E., Demenchuk P.Yu. Perspectives of institutialization of creative practices in the system of higher school // Vestnik of the Far East regional methodology center. Vladivostok, 2013. - P. 205-209.

[23] Khasan B.I. Modern Conflictology: Between Fear of Conflict and Love to Conflict // Journal of Siberian Federal University. Humanities \& Social Sciences. - 2014. - № 4. - Volume 7. - S. 562-565. 